ALPHA N $^{\circ} 26$ / Julio 2008 (9-28)

ISSN 0716-4254

http://alpha.ulagos.cl

\title{
LA INSERCIÓN DE LA LENGUA MAPUCHE EN EL CURRÍCULUM DE ESCUELAS CON EDUCACIÓN INTERCULTURAL: UN PROBLEMA MÁS QUE METODOLÓGICO ${ }^{1}$
}

The inclusion of the Mapuche Language in the Curriculum of Schools with Intercultural Education: a more than methodological problem

\section{Pilar Álvarez-Santullano B.* Amílcar Forno S. **}

\begin{abstract}
“Todo pueblo que conserva su lengua materna debe considerarla en todo momento como primera lengua, como si fuera la única que existiera en el mundo". ${ }^{2}$
\end{abstract}

\section{Resumen}

En este artículo nos proponemos relevar los sentidos, motivaciones y significados que subyacen a la inserción de la enseñanza de la lengua mapuche en escuelas con programa de educación intercultural situadas en territorio mapuche huilliche y ponerlos en juego con las ideologías que sustentan el currículum y que articulan las concreciones escolares de su enseñanza. Sostenemos que en las escuelas en las que el énfasis educativo está en la revalorización de la identidad políticocultural del pueblo mapuche, la enseñanza de la lengua se resitúa en una perspectiva liberadora, mientras que en las escuelas donde la identidad se individualiza y se elabora sobre un currículum culturalista y deshistorizado, la lengua mapuche cuenta para su enseñanza sólo con espacios fragmentados - discontinuos en el tiempo- en los que a, su vez, se ve supeditada a los contenidos disciplinarios tradicionales del currículum oficial, reafirmando de esta manera — y contrariamente a lo que se hubiera esperado— - su condición de lengua subordinada.

\footnotetext{
${ }^{1}$ Resultados del Proyecto Fondecyt N ${ }^{\circ}$ 1050634: “Construcción social y concreción curricular del discurso de la Educación Intercultural Bilingüe: interpelaciones en contextos mapuchehuilliches”, financiado por Conicyt. Incluye entrevistas con docentes y directores de escuelas con EIB realizadas por los investigadores Pilar Álvarez-Santullano, Amílcar Forno y Rita Rivera, y por Johana Godoy, alumna de la Universidad de Los Lagos, como parte de su tesis -integrada a este proyecto- para optar al título de Profesora en Educación Media con Mención en Lengua Castellana y Comunicaciones y al grado de Licenciada en Educación. Una versión preliminar de este trabajo fue leída en el XVII Congreso de la Sociedad Chilena de Lingüística (octubre de 2007) en la Universidad de Concepción, Chile.

${ }^{2}$ Anselmo Nuyado Ancapichun, en "Estudio sobre la lengua mapuche huilliche”, presentado como parte fundamental del Documento Memorial Año 2000 de la Junta General de Caciques del Futawillimapu, territorio mapuche huilliche.
} 


\title{
Pilar Álvarez-Santullano - Amílcar Forno
}

Palabras clave: lengua mapuche, educación intercultural.

\begin{abstract}
In this article we aim at underscoring sensens, motivations and meanings underlying the insertion of the teaching of the Mapuche language in schools, located in Mapuche Huilliche territory, that are submitted to intercultural education programs, and put them into play with ideologies that underpin the curriculum, and articulate the school concretions of the teaching of the language. As part of our findings, we claim that in schools where the educational emphasis is on the revaluation of the politicalcultural identity of the Mapuche people, the teaching of the language is resituated in a liberating perspective; whereas, in schools where identity is individualized and worked out on a cultural curriculum devoid from history, the Mapuche language education counts only upon fragmented spaces, discontinued in time, which in turn, is subjected to traditional disciplinary contents of the official school-curriculum, reassuring -against expectations - its status of subordinate language.
\end{abstract}

Key words: mapuche language, intercultural education.

La enseñanza de la lengua mapuche en la escuela es un tema que tiene una larga y controvertida secuencia histórica, evidencia por lo demás de que la discusión sobre este tema va más allá de los actuales problemas metodológicos que emergen en la discusión actual sobre el asunto. Considerada durante la época de la conquista "lengua del Reyno de Chile" y promovido su estudio riguroso por los misioneros como instrumento de evangelización- a partir del período de la Independencia Nacional se ve afectada, junto con el resto de la cultura, la economía y la sociedad mapuche, por las políticas de la emergente nación chilena, nación que surge, de acuerdo con Pinto (2001), inspirada en tres principios fundamentales: una extremada vocación centralista, una obsesión por la unidad y una fuerte tentación de imitar otras experiencias, principalmente la europea. Todo ello redunda en la férrea voluntad de las autoridades políticas chilenas de homogeneizar cultural e idiomáticamente a la nación chilena.

Consecuencia directa de ello fue la prohibición factual de hablar la lengua mapuche en las escuelas. Su uso fue sancionado duramente por los maestros y los alumnos que no lograban evitar el empleo de algunas palabras de su lengua solían ser objeto de burla de sus compañeros de estudio. Por actuales relatos de vida de jóvenes docentes mapuches sabemos que no han pasado dos décadas desde que esto aún ocurría en territorio huilliche. El estigma de ser mapuche en la escuela se corporizó fuertemente en la lengua, vestimentas y comidas. Éramos bichos raros es una metáfora acuñada por una docente huilliche que ilustra este fuerte sentimiento de estar siempre "fuera de 


\section{La inserción de la lengua mapuche}

lugar” en la escuela — de ser advenedizo — pero, además, advenedizo obligado, porque la escuela es ineludible

No hablábamos propiamente mapuzugun, pero sí nuestro padre [quien] al lado siempre nos decía palabras en mapuzugun. Esas palabras, muchas veces cuando uno es niño, las utiliza en el colegio, las dice por ejemplo, las habla, nosotros les dábamos otros términos (...) No me acuerdo en este momento específicamente qué fue lo que me pasó, pero sí me acuerdo que todo el mundo se reía en este caso, cuando nosotros, al perro nosotros le decíamos txewa, así muchas cosas más... el nombre de las aves, de los árboles... y todo el mundo se reía en clases, se reía de nosotros que según [ellos] hablábamos mal. Y el resto de la discriminación, el hecho de nosotros ser de tez diferente, vestirnos diferente. Nunca andábamos a la moda, siempre andábamos con ropa súper sencilla, ropas hechas de lana y eso era para los demás, éramos, nosotros éramos bichos raros.

La risa opera como mecanismo de sanción social y de de-solidaridad, como recurso que relega lengua y costumbres mapuches al lado de afuera de la escuela y de lo normativo. La escuela es institución no-mapuche y la risa -que actúa como recurso de exclusión de la diferencia y cohesión entre supuestos iguales- - construye al otro lado la autoextrañeza, la propia figura desvirtuada y remitida al silencio y ocultamiento como posibilidad de neutralizarse. La escuela es un lugar en el que, junto al aprendizaje de los saberes disciplinarios, se aprende a poner en suspenso los elementos sancionados de la identidad comunitaria. Así, la decisión individual y colectiva de abandonar la lengua es consecuencia de políticas fuertemente colonizadoras que inducen el "borramiento" del otro. Al respecto, Calvert (2005) ha subrayado la funcionalidad del discurso colonizador al construir las lenguas indígenas como poco aptas para la sociedad moderna

El discurso colonial sobre la lengua no sólo es racista, o despreciativo: ésas sólo son sus manifestaciones más ligeras. Es —ante todo y más profundamente- funcional, (...) la extirpación de las culturas locales, de las lenguas locales a la que tiende este discurso colonial, presupone una cultura y una lengua de reemplazo; es el mito de la asimilación, que tantas veces reapareció bajo distintas formas (153).

La situación parece estar cambiando actualmente: las escuelas focalizadas por el Programa Orígenes han iniciado un proceso de incorporación de la educación intercultural bilingüe (EIB) en su currículum, en el que uno de sus componentes importantes es la enseñanza de la lengua mapuche, incluso, en escuelas de comunidades con muy baja o nula vitalidad lingüística. Así, 


\section{Pilar Álvarez-Santullano - Amílcar Forno}

todo apunta a indicar que la enseñanza de la lengua mapuche en la escuela se inscribe en un intento de revertir el proceso de devastación y sustitución que la afecta.

La historia de fortalecimiento y revitalización de lenguas nos ha enseñado que este proceso ha sido posible en comunidades lingüísticas que toman conciencia y forma de comunidades políticas, en el que la lengua ha sido entendida como un derecho de la colectividad y en el que la minoría lingüística ha podido conseguir algún tipo de autonomía política, como ha ocurrido en los casos del francés en Québec, del hebreo en Israel y del catalán en Cataluña (Siguan, 2001).

De allí que en el actual contexto de instalación de la educación intercultural en las escuelas, nos interesa dar cuenta de los sentidos y significados con que los docentes emprenden y/o acogen la incorporación de la enseñanza de la lengua mapuche en el currículum escolar y el vínculo entre estos sentidos y los que - actual e históricamente- manifiesta el entorno sociopolítico mapuche para la lengua, su uso y enseñanza.

En suma, se intenta abordar las funcionalidades y relevar en el discurso escolar y dirigencial, en el contexto de los cambios de políticas antes señalados, las solidaridades y de-solidaridades que se construyen en relación a la lengua mapuche. Estas tensiones y disputas tienen lugar en el discurso - práctica social y objeto de deseo en el que se construyen y circulan representaciones sociales, saberes y conocimiento-, en los enunciados que constituyen los discursos y que exhiben la procedencia y lugares de sujeción de éstos, que analizamos a partir de entrevistas realizadas a docentes mapuches y no mapuches de cuatro escuelas que desarrollan proyectos de Educación Intercultural en las regiones de Los Ríos y de Los Lagos y de dirigentes mapuches - tradicionales y funcionales - de las comunidades en que las escuelas están insertas.

\section{EL DISCURSO DE LA DIRIGENCIA MAPUCHE: LA LENGUA EN LA INTERLOCUCIÓN CON EL ESTADO}

1.1. La dirigencia tradicional. Conforme a los planteamientos de Pinto (2001), la clase dirigente chilena construyó la nación inspirada en la sobrevaloración de la sociedad europea y el menosprecio de lo propio. Su obsesión por la unidad favoreció una educación elitista y una escuela de intolerancia, que para homogeneizar la lengua y la cultura nacional prohibió y aplastó sistemáticamente todo atisbo de diversidad. Por otra parte, este estado de "extremada vocación centralista", fue sordo a muchas de las demandas regionales, entre ellas — por cierto- las del pueblo-nación mapuche. Así

ocurrió también con los memoriales, documentos escritos por la dirigencia 


\section{La inserción de la lengua mapuche}

huilliche tradicional con histórica constancia a las autoridades de los gobiernos de turno, de los que Foerster y Vergara (2001: 44) expresan: "No conocemos ningún documento de gobierno en el que explícitamente se reconozca su validez. Menos que sea considerado como la base de las reformas legales implementadas desde la instauración de la República”.

Entre estas demandas y exigencias históricas, las vinculadas a la lengua mapuche y su enseñanza en la escuela fueron tema reiterado en la búsqueda de interlocución de los caciques mapuche huilliches con el estado chileno, tema que hoy continúa vigente en el discurso de la dirigencia indígena. Ya en el Memorial de 1936, los caciques firmantes expresan la necesidad de que sea el mismo pueblo mapuche responsable de su educación, para lo cual piden colegios propios en los que pueda enseñarse el idioma nativo mapuche

Siendo la instrucción la base de todo progreso, los caciques solicitan colegios propios dentro de sus reducciones o tribus (...) además veríamos con sumo agrado, V.E. que de la instrucción folklórica se nombre una comisión para que estudie el idioma indio-mapuche, se hagan textos de enseñanza que se destinarían gratuitamente en los colegios fiscales de la República y en los nuestros para que los indiosmapuches y mestizos chilenos se posesionen del idioma nativo de los padres de la raza chilena de este país.

En los memoriales se reclama el derecho a la enseñanza de la lengua mapuche y el derecho a hablar en lengua propia. Estos reclamos en favor de la instrucción en lengua mapuche forman parte del derecho al reconocimiento; intento de revertir la negación ontológica comportada en el silencio de la lengua en la que se funda, se dice y se reconoce el ser mapuche. Seguir el memorial del 1936 "los particulares extranjeros y nacionales dicen que no hay indios-mapuches con el fin exclusivo de quitarnos nuestras tierras”. La interpelación que exige la enseñanza del idioma mapuche (que más tarde será retomada por la dirigencia actual), se extiende en este Memorial hacia la sociedad mestiza por cuanto la lengua mapuche es "el idioma nativo de los padres de la raza chilena” y es portadora de "la civilización incaica del inca Atahualpa; que es más moral que la civilización europea”, con lo que se reconoce en la lengua un valioso sustrato originario de la nación, legitimándose su derecho a ser valorada por su pre-existencia y carácter pancultural que la vincula con el Imperio Inca ${ }^{3}$.

En los documentos oficiales del cacicado, la preocupación por los destinos de la educación y enseñanza de la lengua es constante. El siguiente

${ }^{3}$ Relación recurrente ésta - entre el mundo huilliche y el mundo incaico- que aún ha sido poco estudiada. Algunos indicios de esta relación se pueden ver en Contreras, 1991. 


\section{Pilar Álvarez-Santullano - Amílcar Forno}

texto forma parte del documento de 1985 emanado del Tercer Congreso de Caciques de la Butahuillimapu (punto 2.3.) se reclama

El sistema de educación huinca no responde a los requerimientos culturales del mapuche, porque desconoce la cultura mapuche, sometiéndola a nuevos designios, especialmente exterminando su expresión cultural.

Por tanto, es necesario la formación de escuelas en las mismas comunidades dirigidas por maestros o profesores mapuches.

Proyectar el conocimiento del idioma y considerarlo a lo menos obligatorio en las escuelas comunitarias. La educación y valores culturales deben estar velados por las autoridades máximas de la comunidad.

A través de la modalidad deóntica, el discurso de los memoriales va alertando sobre la necesidad de una política — ya no de tolerancia, sino de protección - hacia la lengua mapuche. Cinco años más tarde aparece el documento que contiene el análisis y la propuesta más importante sobre la lengua mapuche en su variedad huilliche, como es el Documento Memorial Año 2000, en el que la dirigencia presenta un estudio sobre la lengua mapuche huilliche como una decisión fundamentada en un derecho inmemorial

[La Junta de caciques] Han decidido presentar su estudio de la Lengua Mapuche Huilliche, con el derecho inmemorial de nuestro[s] antepasado[s] que han sido llevado[s] al exterminio de nuestro Pueblo Mapuche Huilliche. Gracias al Espíritu de nuestro padre el Chau Xrokin no ha permitido que este Pueblo sea desaparecido en el mundo, que todo[s] exigimo[s] nuestra libertad.

El discurso del Memorial del 2000 se funda sobre ejes construidos en el discurso histórico de los caciques. Los memoriales reiteran la relación entre lengua y sobrevivencia del colectivo, entre lengua y continuidad histórica del grupo. Como se trata de un reclamo del pueblo mapuche huilliche y de una determinación de sus dirigentes es su lengua —nombrada y transcrita en otra parte del texto como "Ce Sumun" ${ }^{-}$la que se invoca para la sobrevivencia del pueblo que la habla. Con este nombre específico de la lengua (Ce Sumun)

\footnotetext{
4 Desde nuestros primeros estudios sobre la lengua mapuche, señalamos que la variedad huilliche era nombrada en San Juan de La Costa como chezugun. En esta época, a veces usamos la transcripción más cercana a la fonética tsesungun, otras veces, siguiendo el alfabeto unificado usamos chesungun o chedungun según variantes que alternan en los hablantes. Actualmente, usamos chezugun siguiendo el alfabeto Azümchefe, esfuerzo reciente de normalización grafemaria de la Corporación Nacional de Desarrollo Indígena (CONADI).
} 


\section{La inserción de la lengua mapuche}

se signa también la diversidad en que se reconoce el pueblo huilliche respecto de otras facciones de la sociedad mapuche, discurso que - como veremos más adelante - será retomado en el currículum que incluye la lengua como elemento vinculante con la realidad sociopolítica del pueblo mapuche huilliche.

1.2. La dirigencia mapuche no tradicional. En el discurso actual de los dirigentes mapuches no tradicionales, ${ }^{5}$ la funcionalidad de la lengua mapuche se complementa con los conceptos de desarrollo y emancipación. Como explica una dirigente y concejala comunal, hablar mapuzugun es clave para el desarrollo social y económico mapuche. El desarrollo económico es posible porque la lengua sirve "para enfrentar una nueva estrategia de desarrollo" en la que la lengua "nos sirva hoy día, por ejemplo, para rellenar de conocimiento y contenido lo que es el agro, el etnoturismo (...)”. Saber hablar la lengua mapuche permitiría un desarrollo posible en el contexto de la globalización. No sólo se trata de que la comunidad chilena tenga conciencia de la lengua nativa sino, también, de que ésta sea reconocida por extranjeros: "que un visitante de afuera venga y vea que rayen es flor, o que rayenlemu es "flor en la cordillera”, que él sepa, así como nosotros sabemos lo de inglés". La lengua colabora, también, en el desarrollo social, en que "la restitución de nuestras organizaciones sociales tengan un rol protagónico, con participación y actores, que decidan, que no sean consultados para que otros decidan”.

De esta forma, para la dirigencia mapuche no tradicional, la lengua viene a superar y a completar la valoración que suele otorgársele como recuperación de lo ancestral. La lengua forma parte de una estrategia política que permite reconstruir un lugar de enunciación, pues la lengua construye una territorialidad propia en la que el resto de la sociedad, la dominante, debe ingresar para dialogar. Se trata de darle un giro al poder. Así como la sociedad mapuche ha estado obligada a hablar y a escribir en castellano; así como el estado chileno ha generado un espacio de enunciación en castellano y ha obligado al mapuche a construirse en interlocutor en lengua hispana, ahora es tiempo de construir al otro en interlocutor en lengua mapuche. Desde allí, la enseñanza de la lengua requiere inmediatez y amplitud. "Si yo entre mapuches voy a conservar mi idioma para que sea valorado en el futuro, no me sirve. Tiene, la sociedad winka — que le llamamos nosotros- tiene que aprender el idioma. Cómo voy a valorar y cómo me va a entender a mí si él no sabe nuestro idioma".

\footnotetext{
${ }^{5}$ Por dirigentes tradicionales huilliches entendemos a quienes desempeñan cargos vinculados directamente con el cacicado. En el grupo de dirigentes no tradicionales incluimos a los presidentes y otros directivos de comunidades, asociaciones y organizaciones mapuches y a quienes ocupan cargos de representación política en el sistema estatal.
} 


\section{Pilar Álvarez-Santullano - Amílcar Forno}

En esta necesidad de construir al interlocutor, incorporando la lengua mapuche en los centros de decisión y poder, la dirigente interpela al Estado para un cambio en la política estatal, en la necesidad de pasar de un esfuerzo muy superficial del Estado [definido por ella como "folclórico"], a una política lingüística más seria y sistemática, que permita un cambio en los ejes de decisión, conocimiento y poder, en las instituciones estatales, en la escuela y en el diálogo intercultural de la sociedad winka y mapuche

lo primero, si nosotros queremos valorar el idioma, es que debe ser hablado por todos los agentes que van a contribuir a ese desarrollo, no sólo una parte [la mapuche]. Si a nosotros nos obligaron a aprender español, nos alfabetizaron en castellano y nosotros aprendimos a hablar castellano - hoy hablamos castellano, bueno o malo, pero lo hablamos - por lo tanto, hay que enseñar a hablar idioma [mapuche] para que se pueda tener un interlocutor, varios. De lo contrario no vamos a tener con quién hablar. Para hablarlo entre mapuches y decirnos las cosas que ya sabemos no nos sirve. Nosotros tenemos que llegar al corazón de la contraparte de la sociedad mayoritaria que hoy día decide por ti, hoy día para los mapuches deciden... los blancos. No deciden los mapuches.

Este desafío (enfáticamente acentuado por la dirigente: “el desafío... aquí hay un desafío, no una gana, un desafío”) de desbordar las fronteras actuales de la lengua apunta a la emancipación del pueblo mapuche, pues, la lengua permitiría deconstruir la subalteridad: "[la lengua mapuche] tiene que llegar a ser importante en nuestra política de desarrollo como pueblo, y no sólo como pueblo, sino como sociedad hoy día dominada”

\section{LA EDUCACIÓN INTERCULTURAL EN EL MARCO ESTATAL}

La Educación Intercultural Bilingüe (EIB) en Chile responde a un tipo de educación que el Estado ha venido desarrollando para superar problemas educacionales de los pueblos indígenas del país. La EIB estatal es una experiencia de política educacional muy reciente. Se inicia a fines de los 90 con la puesta en marcha de proyectos piloto financiados por el Ministerio de Educación en escuelas seleccionadas para este propósito y con algunos proyectos piloto de EIB financiados por Conadi.

El Ministerio de Educación a través de su programa de EIB suscribe la convicción de que "fortaleciendo la identidad se mejoran los resultados" (Huenchullan: 207). Este constreñimiento a lo pedagógico, por sobre otras metas y demandas de los actores locales, es un discurso situado desde los lineamientos internacionales del Banco Interamericano de Desarrollo (BID), institución que facilita al Estado chileno, en calidad de préstamo, los fondos 


\section{La inserción de la lengua mapuche}

para la implementación del Programa Orígenes. De hecho, el objetivo de las políticas públicas del Ministerio respecto de la EIB, se encuentra explicitado en parte del anexo del Contrato de Préstamo firmado entre el Ministerio de Planificación y Cooperación del Gobierno de Chile y el BID

Como parte de la política pública y de las acciones que ya se venían desarrollando desde el Ministerio de Educación, se incorpora, finalizando el año 2001, un nuevo componente [el Programa Orígenes], el cual apunta a reforzar el mayor objetivo del PEIB, a saber, la creación de la propuesta pedagógica: "para el mejoramiento en amplitud y calidad de los aprendizajes correspondientes al currículo nacional de enseñanza general básica que propone la Reforma de la Educación, en 162 escuelas donde estudian niños y niñas de los pueblos indígenas aymara, atacameño y mapuche (Huenchullan: 215).

De esta manera, los objetivos se “obligatorizan”. La EIB ministerial refuerza sus metas y objetivos y se invisibilizan las demandas para construir una EIB propia desde el mundo mapuche. La inserción de la lengua mapuche en la enseñanza forma parte de una política remedial para superar el déficit en la autoestima de los niños indígenas, de manera que, superados estos problemas, sea posible exhibir mejores resultados en los procesos de enseñanza aprendizaje. Por esta vía, la educación intercultural baja a las escuelas como uno más de los Programas del Ministerio de Educación que permitirían mejorar la calidad y equidad de la educación. Tanto Mineduc como Conadi, en tanto instituciones del Estado, legitiman las políticas estatales que se establecen para la población indígena. Sin embargo, tienen dinámicas distintas, probablemente derivadas de las particulares historicidades de cada una y de su mayor o menor centralismo. Desde el comienzo, la gestión de los primeros proyectos de educación intercultural entre Mineduc y Conadi difieren en aspectos que, finalmente, resultarán claves para mantener o distanciarse del modelo centralizado de Educación Intercultural. A diferencia de Mineduc, Conadi no focalizó escuelas sino que llamó, mediante concurso, a escuelas particulares subvencionadas para desarrollar proyectos piloto de EIB, formulados por las propias escuelas, en la misma época en que se comienzan a implementar planes piloto en las escuelas municipales focalizadas por el Ministerio de Educación. En la actual Región de Los Lagos a esta convocatoria se presentaron dos escuelas. En una de ellas, cuya sostenedora es mapuche huilliche, la educación intercultural se replantea y se reelabora en términos de educación mapuche, generando procesos educativos integradores, en los que por una parte se intenta responder a las políticas y mediciones estandarizadas del Ministerio, a la vez que la escuela se 


\section{Pilar Álvarez-Santullano - Amílcar Forno}

constituye en espacio físico e ideológico de un modo de pensar, cuestionar y responder políticamente a la diferencia.

Es en esta red de construcción de la interculturalidad como proceso educativo complejo, donde la enseñanza de la lengua mapuche ingresa al currículum escolar. La complejidad del proceso se basa en las distintas modalidades de entender e implementar la EIB que muestran las escuelas. Hay algunas que revalorizan más la identidad cultural desligada de lo político y otras que revalorizan más la identidad política cultural del pueblo mapuche. Y entre éstas, hay algunas que acentúan procesos de gerencialidad, en las cuales los proyectos de EIB son intercambiables por otros proyectos de mejoramiento educativo que aporten más y mejores recursos para mostrar eficientes resultados de aprendizajes que le permitan a la escuela subsistir en un medio signado por la competencia y el control. Hay otras escuelas que ponen el énfasis en el mejoramiento de la autoestima de los niños para lo cual utilizan recursos lúdicos y escenográficos con el fin de maquillar y mejorar la imagen de la cultura y del mapuche. Hay, también, escuelas — siendo la mayoría de los casos - que cierran las puertas a cualquier conflicto político de sus comunidades, mientras que otras las abren para que la escuela sea precisamente el lugar donde se encuentren autoridades winkas y mapuches para parlamentar sobre problemas actuales y concretos, en presencia de apoderados y alumnos. Evidentemente estos modos de construir la interculturalidad no son exclusivos de cada escuela. Algunos de ellos se entremezclan, se solapan unos con otros y, fundamentalmente, dependen de los actores que estén involucrados en este proceso. Como consecuencia, la incorporación de la lengua mapuche y sus concreciones curriculares en las escuelas responde a motivaciones distintas. En el proceso se pueden generar niveles avanzados de reflexión o, bien, puede incluirse la lengua como contenido lábil y los sentidos y significados que se le asigna a su inclusión se entrecruzan con los sustratos ideológicos que sustentan el currículum de cada escuela los que, finalmente, articulan las concreciones escolares de su enseñanza. Por ello, nos acercamos al proceso de curricularización de la lengua mapuche fijando, especialmente, la atención en las diferencias que pudieran presentar escuelas con educación intercultural bilingüe (EIB) de raigambre ministerial, y en escuelas con educación mapuche (EM).

\section{CURRICULARIZACIÓN DE LA LENGUA MAPUCHE EN LAS ESCUELAS CON EIB}

3.1. La enseñanza de la lengua en la escuela con educación intercultural. Las cuestiones que más relevancia suelen adquirir en las escuelas con educación intercultural bilingüe son preguntas relativas a qué contenidos de la cultura 


\section{La inserción de la lengua mapuche}

mapuche seleccionar, cómo éstos pueden ser organizados y en qué lugares (subsectores de aprendizaje) pueden tener cabida. Esta forma instrumental de pensar el currículum, como un plano en el cual podemos situar y distribuir los contenidos, responde según Barbosa (1997:13) a una influencia de la psicología del comportamiento, que contribuye en el desarrollo de una perspectiva en la que el foco de los estudios del currículum se desplaza hacia un plano en que se detallan sus elementos, su organización y sus interrelaciones. En el currículum restringido a la idea de plano, las cuestiones básicas pasan a ser ¿qué es lo que debe un plano contener? y ¿cómo formularlo? Estas son modalidades de planificación curricular que, como dice Corazza (1997:115) al no ser historizadas, no pueden ser identificadas como construcciones culturales/educacionales y no permiten proceder a un trabajo de crítica distanciado.

Despojado —en la mayor parte de las escuelas con educación intercultural- el currículum de su dimensión sociohistórica, asumido en su carácter neutro, no logra ser visualizado como proyecto educativo transformador por lo que los espacios de instalación de contenidos mapuche no trascienden miradas episódicas, aun cuando en determinados subsectores se construyen objetivos complementarios a través de los cuales se intenta rescatar la cosmovisión indígena.

En cualquier caso, la lengua mapuche representa un problema mayor para la escuela, fundamentalmente por la enorme carencia de profesores preparados para ello, por lo que la enseñanza de la lengua mapuche no se declara como objetivo prioritario. Pero, como los programas son de educación intercultural bilingüe, las escuelas presentan diversas soluciones para incorporar los contenidos lingüísticos, con fórmulas y matices distintos, incluso, en una misma escuela, según el modo como cada docente entienda o priorice la interculturalidad.

En algunas escuelas, el programa de educación intercultural prioriza en uno o más niveles de la enseñanza básica el subsector Comprensión del medio natural, social y cultural, siendo el más recurrente como eje de inclusión de contenidos mapuches. La enseñanza de la lengua mapuche —o más bien, su emergencia- es transversal a éste y los demás subsectores. Este tipo de intervención produce una fragmentación de la lengua mapuche que queda supeditada a objetivos disciplinarios del programa oficial. Una docente de educación básica explica cómo aprovecha ciertos espacios - siempre y cuando no interfiera mucho con el Programa que debe cumplir- para traer a presencia la lengua mapuche

(...) pero las palabras de uso frecuente, por ejemplo, el saludo, cómo están, cómo te llamas, cosas así, lo que se ve acá, el abecedario de 


\section{Pilar Álvarez-Santullano - Amílcar Forno}

repente, esas cosas... más no, porque yo tengo un programa... Y en Comprensión del medio trabajamos, por ejemplo, ahora estábamos con la orientación, y ahí pasamos los puntos cardinales, ahí como que uno mezcla, (...) Como estamos aquí, uno tiene su contexto, o sea, de la naturaleza ellos tienen que hablar...y ahí aprovecho yo de hacer estas cosas, porque no está como asignatura.

La enseñanza de la lengua mapuche supeditada a saberes de primer orden constituidos en contenidos legitimados por el currículum oficial queda, así, replegada a la buena voluntad de los docentes y a la posibilidad de aparecer cuando de alguna manera sea posible evocarla en taxonomías numéricas, de la naturaleza, del cuerpo humano o de cualquier otro tipo, en una traducción de la epistemología científica occidental. La enseñanza se complementa con fórmulas de saludos y frases breves —metodología comunicativa desarrollada en la enseñanza instrumental de lenguas extranjeras - pero que, aplicada a la enseñanza de una lengua indígena, choca inevitablemente con la resistencia a replicar su uso en espacios de la sociedad donde mantiene el desprestigio que signa al grupo que la habla. La metodología comunicativa enfocada en el uso instrumental del lenguaje contextualiza situaciones neutras al invisibilizar posiciones de subalternidad colectiva; por ello no hace posible un reposicionamiento que permita subvertir actitudes lingüísticas y sociales generadas en históricas relaciones de dominación.

En otra forma de inserción curricular, la lengua mapuche no se enseña transversalmente en los subsectores, sino que se desplaza hacia los talleres de lenguaje, currículum periférico cuyos contenidos no son evaluados, y en los que el mapuzugun resulta, apenas, una incursión ocasional frente a la preeminencia del castellano.

El inevitable resultado de estas soluciones es la marginación o la dispersión sin sentido de la lengua mapuche y la frustración de profesores que intuyen que el camino emprendido no tiene largo alcance. Cuando la lengua mapuche no se entiende como posibilidad de deconstruir relaciones de colonización, no encuentra un sustento actitudinal que la fortalezca en el aula o en otros espacios posibles de uso. Se debilita en la fragmentación, marginación y en otros procesos, como la discontinuidad temporal con que se intercala en el currículum. La enseñanza de la lengua deviene en espacios de concesión que la institución escuela otorga, posibles siempre y cuando los docentes encuentren momentos que no alteren el programa oficial por el cual habrá que responder ante las mediciones de pruebas nacionales que singularizan la eficiencia de la escuela. 


\section{La inserción de la lengua mapuche}

Es la lengua mapuche la que al entrar a la escuela tiene que adaptarse, ocupar los intersticios del sistema que queden disponibles en el currículum que opera como espacio de subalternización del niño, al que se le impone una lengua ya subalterna, al que se le insiste en que es la suya y que debe asumir como propia sin liberación previa del signo negativo que ésta trae consigo.

En general, la enseñanza de la lengua mapuche en las escuelas con educación intercultural ha ocupado un lugar secundario frente a la inclusión de otros elementos culturales mapuches y, del mismo modo, en los discursos docentes de escuelas apegadas al modelo ministerial, tema que tampoco es fuente de reflexión. Circunstancialmente, los docentes de estas escuelas esbozan alguna opinión sobre el sentido de incluir lengua mapuche en el currículum escolar y, cuando ello ocurre, surge a menudo un referente externo en cuya mención subyace la lógica de la verticalidad: se enseña lengua mapuche porque el establecimiento ingresó al Programa Orígenes, porque se han recibido textos para trabajar en lengua mapuche, o bien, porque como lo expresa una docente "tenemos casi el 100\% de los niños mapuches, entonces yo implementé la sala con mapuzugun”, en una evocación clara al discurso de la Ley Indígena 19.253 (artículo 28) que estipula el "uso y conservación de los idiomas indígenas, junto al español en las áreas de alta densidad indígena”, enunciado que, también, recoge el Ministerio en su Programa de EIB.

La justificación para la inserción de la lengua mapuche en la escuela se desenmarca del contexto extralingüístico, de la asimetría de poder que comporta la estructura social global y se elabora como respuesta a la obligatoriedad y/o a la pertinencia numéricamente justificada de contar con alumnos mapuches. De este modo, la lengua mapuche ingresa a la escuela como un componente del programa global de educación intercultural, aceptado y asimilado por las escuelas que han sido convencidas - tras una resistencia inicial - de sumarse a un programa estatal, proceso en que la interculturalidad transita desde arriba hacia abajo.

3.2. La enseñanza de la lengua en la escuela mapuche. El problema de la carencia de profesores preparados para enseñar la lengua mapuche ${ }^{6}$ es común a las escuelas de las regiones de Los Ríos y de Los Lagos. Sin embargo, en escuelas que propugnan una educación endógena, con fuerte compromiso político, en lugar de constreñimiento, parece que la lengua se calara por todos los espacios posibles, que la escuela toda se involucrara para aprender a

\footnotetext{
${ }^{6}$ La situación contrasta con la enseñanza del inglés, que se imparte en forma obligatoria en el sistema escolar chileno desde $5^{\circ}$ año básico y para lo cual se ha invertido en la capacitación en inglés de profesores con formación general básica.
} 


\section{Pilar Álvarez-Santullano - Amílcar Forno}

hablarla. Hablar la lengua mapuche en estas escuelas forma parte de un conjunto complejo de prácticas que definen de alguna manera las características más deseadas de un alumno.

Marrian agarró la txutxuka po’ y Marrian no había tenido ya en dos años información [mapuche]. No, él siempre en la ciudad y él, no sé po', agarró la txutxuka y se puso a la cola de la banda, entonces iyo no sé! Porque hay un tiempo para [aprender a] tocar la txutxuka y él observando, él lo hace y lo hace bien. O sea, yo creo que ése va a ser un buen interrogador también, ése también va a ser un buen interrogador. Usted le pasa la bandera y va a interrogar. Ése... además conoce mucho, tiene habilidades también con el idioma [mapuche], o sea, no se le olvida. Usted le va a enseñar lengua y no se le va a olvidar, es súper hábil, despierto...

Hablar lengua mapuche es el objetivo central en estas escuelas, aunque los resultados no sean medidos a través de pruebas nacionales. Si la escuela no puede lograr que sus alumnos salgan como competentes bilingües, porque todos - incluidos los profesores - están aprendiendo, lo importante es que el ambiente de aprendizaje, holístico y de compromiso, genera las potencialidades para que los alumnos continúen en este aprendizaje en los siguientes niveles de enseñanza, ya fuera de su escuela. Así lo demuestra este profesor refiriéndose a Cristóbal, un ex alumno, que los vuelve a visitar para los actos mapuches.

Cristóbal les mandó todo en lengua no más, no les mandó nada en español, todo en lengua no más, en cambio el otro se lo dijo en español. No, él pura lengua no más.

Éstas son palabras cargadas de valoración positiva hacia el uso de la lengua como demostración de poder: Cristóbal no, "les dice" todo en lengua no más, Cristóbal "les mandó” todo en lengua, poder que, de alguna manera, alcanza también a la escuela.

En otras ocasiones, la lengua se comparte más generosamente. En el diálogo pedagógico, los docentes constantemente matizan su habla con palabras mapuches que van traduciendo en el mismo momento cuando suponen que su interlocutor no las conoce. Esta traducción constituye, más bien, una explicación que acentúa el valor positivo de la cultura.

Entonces, ése es el contenido de la ñukekütralwe porque ahí se está [alrededor de] el fuego, estaba en la ruca, ahí uno se sentaba a la orilla del fogón, tenía su catre, su katxon ahí donde dormía con su pellejito. Ahí se hacía todo, ahí se cocinaba, se enterraba la papa, se hacía todo el 


\section{La inserción de la lengua mapuche}

quehacer ahí, se bailaba, se cantaba, se hacía romanceo, se hacia ülkantun, por eso es la ñuke...

Hay momentos en que la reiteración de términos mapuches entremezclados con el castellano parece anunciar el comienzo del desarrollo de una interlengua, en que cada miembro de la escuela hace esfuerzos por incorporar palabras, aun cuando la fonética sea a veces disímil

yo les dije [a los alumnos] "ustedes pisaron aquí y esta escuela es intercultural y ustedes hacen lo que se dice", entonces ahora ya hacen ¡mari mari kümelekaimi! ¡chaino!, eh, müchay, hasta müchay, un ratito van por ahí, mürkay. Eso no lo decían, esas palabras las llevó a la sala la Jaquie y ahora todo el mundo está hablando lo mismo. Entonces, mi hijo dice que son muy algunos los que saludan cuando llegan al furgón. El que nunca se olvida es Pancho, todos los días saluda en lengua cuando sube, Panchito de la Angélica y arriba el chiquitito ¿cómo se llama?, el de la Cristina...

Junto a los saludos y el empleo de vocativos (ñaña, lamwen, peñi, entre otros) suelen aparecer, con cierta frecuencia, otros términos que remiten a aspectos muy propios de la cultura mapuche, que caben en la noción de realia, esto es, "objetos y conceptos específicos acuñados en el vocabulario de una lengua y que son característicos para la comunidad que la habla” (Neubert y Nielsch, citados en Cartagena 1998:9) como se ve en el siguiente enunciado

para eso se pidió una ley de acuerdo, que ya es una ley winka, no es una ley propia porque el Lonko no tiene ley para eso está el admapu.

La lengua mapuche se intercala y asienta en el habla cotidiana en la medida en que la funcionalidad de la enseñanza de la lengua se asocia fuertemente al diario vivir

porque por aquí entra la ofiza es su entorno, siempre va a correr la oveja y va a ir diciendo ofiza, ofiza, ofiza, amope, amope ofiza , "vamos, ovejas, vamos”, va a ir... lo va a ir aprendiendo, entonces la ñaña le inventó un canto y le dio ritmo, entonces los chiquillos van cantando amope, amope y van cantando todos sus cosas de su casa y lo cantaron el otro día allá donde la Marlene...

Como se ve $-\mathrm{y}$ contrariamente a lo que ocurre en la escuela con educación intercultural - la importancia de la lengua es tema frecuente de reflexión en el discurso de docentes en la escuela que se emplaza educativamente desde lo local como espacio social y políticamente 


\section{Pilar Álvarez-Santullano - Amílcar Forno}

conflictuado. En esta escuela, que intersecta la educación intercultural con una propuesta más propia, ocurre también que el castellano es nominado desde el mapuche - winkasugun - en un compuesto que marca el habla (sugun) del extranjero (winka) ${ }^{7}$. Lengua mapuche y winkasugun se sitúan desde el contexto del conflicto social, en el que grupos lingüísticos comportan intereses antagónicos de los que las lenguas no están exentas. Por ello, su aprendizaje significa la posibilidad de revertir el proceso de dominación, como lo señala una docente

es imposible que por imposición, [por]que de repente nos colonizaron y aprendimos a hablar castellano y luego... después, nosotros perdamos lo que éramos (...) Más de quinientos años nuestro antepasados buscaron cómo poder llevar de nuevo a la sala [la lengua mapuche] y darle más estatus social, el que se merece la Educación Mapuche y se ha logrado a través de luchas del pueblo indígena.

Winkasugun delimita lugares de habla, se refiere al otro sector de la sociedad, y permite construir — como señala Walsh— un locus de enunciación para elaborar la diferencia situadamente: "Las diferencias étnicoculturales no son naturales ni parten de la etnicidad en sí, son fenómenos construidos y reproducidos como parte de una subjetividad y LOCUS de enunciación definidos por la experiencia de colonización y subalternización” (Walsh, 2002).

\section{LA ESCUELA EN SU CONTINUIDAD O RUPTURA CON LA VISIÓN POLÍTICA DE LA DIRIGENCIA MAPUCHE}

Los puntos de encuentro entre la escuela mapuche y la visión de la dirigencia mapuche-huilliche son varios. Uno de ellos se relaciona con el intento de subvertir las relaciones de poder. Aporta a ello el locus de enunciación desde donde la escuela intenta representar una inversión de las relaciones asimétricas de poder. Dicha inversión se sustentaría en "el poder simbólico que el nombrar tiene y que es parte del entramado del Poder" (Hernández s/f). Así, al nombrar el idioma español como winkazugun, el mapuche ejerce el poder de definir, desde sus sentidos y perspectivas, la entidad lingüística del habla castellana. La inversión señalada reactualiza, y recupera en el habla cotidiana, el lofche (comunidad) en la práctica contemporánea de la comunicación inter e intracultural, en la cual, lo que se dice - ya sea en castellano o en chezugun — es, de una u otra manera, signado

\footnotetext{
${ }^{7}$ Con frecuencia winka mantiene una connotación peyorativa, probablemente su conformación se constituya de we 'nuevo' e inka ‘extranjero'.
} 


\section{La inserción de la lengua mapuche}

desde lo mapuche y constituye lo que podríamos denominar "comunicación situada" y/o "comunicación con identidad de origen".

En otro punto de encuentro, la preferencia de la variante dialectal local huilliche chezugun como contenido a ser incorporado en el currículo de la escuela - por sobre la variante más central del mapuzugun que intenta ser impuesta en la escuela por la EIB institucionalizada - es una muestra más de resistencia étnica y afirmación de la identidad local. En la escuela mapuche huilliche se defiende el derecho a enseñar chezugun. Frente al mismo tema, un vicecacique huilliche reclama “(...) por qué a nosotros no nos concretaron lo que queríamos: que es la diversidad de la lengua, el chezugun. Eso es lo que nosotros queríamos, en cambio, hoy día viene avanzando mucho, y los hermanos y los ancestros allá en las comunidades no están muy de acuerdo, [con el avance d]el mapuzugun”. Aspiración que como hemos visto antes, se encuentra enunciada en el Documento Memorial del Año 2000

\footnotetext{
En este año 2000 que estamos viviendo, la Junta General de Caciques hace presente su trabajo, que ha venido realizando en su Organización, un estudio de un Alfabeto de su Lengua Mapuche Huilliche que está acorde con su realidad de la Madre Naturaleza y sus hijos de la Madre Tierra el "Ce Sumun". La exigencia de nuestro Alfabeto propio del Mapuche Huilliche, sea respetado para la escritura del idioma de nuestra Décima Región de Chile el “Ce Sumun”.
}

Por otra parte, el discurso de los docentes releva la orientación formativa de sus alumnos egresados al destacar que varios de ellos han optado por continuar estudios en carreras como etnoturismo y medicina intercultural. Convergen aquí los discursos de los docentes con los de la dirigencia no tradicional en una nueva funcionalidad asignada a la lengua: aportar "conocimiento y contenido propio” para una nueva estrategia de desarrollo. En una perspectiva más amplia, perduran en la memoria dirigencial las tradicionales formas de educación mapuche, como el koyaqtun (argumentación) frente a las que la EIB no deja de tener una resonancia occidental. A esta "mirada huinca", los asesores culturales (educadores tradicionales en el renovado léxico institucional), según los dirigentes, "tuvieron que adecuarse” y en la que el uso instrumental de la lengua mapuche se remite muchas veces a traducir textos occidentales al mapuzugun según un concejal mapuche, esta forma superficial de inserción de la lengua mapuche hace que la dirigencia perciba una desvaloración de ésta y su consideración, solamente, como "un elemento folclórico en lo que es el Programa Orígenes”.

$\mathrm{Y}$ es que hasta ahora la lengua y cultura mapuche se ven reducidas en la EIB de modelo estatal a un uso instrumental y al menos —en algún sentido- 


\title{
Pilar Álvarez-Santullano - Amílcar Forno
}

es posible pensar que la educación intercultural al eludir el contexto social y político, ha sido diseñada, o bien para que la lengua (y también la cultura) se mantengan sólo en espacios intraculturales y no interculturales, o para mantener el statu quo de las relaciones de poder. Si fuera de otra manera - como dice una dirigente que no cree en la profundidad de las intervenciones de la EIB ministerial, ni en su real valoración de la lengua y cultura mapuche — las políticas y la inversión para aprender lengua mapuche serían distintas

...yo apuesto a que un idioma sirve y va a servir, siempre y cuando se den las condiciones sociales, políticas, lingüísticas para que se asuma un desafío nacional. Es que no puede ser que para aprender idioma castellano o español se haya entregado tanta plata, y que hoy día para aprender idioma mapuche o mapuzugun, chezugun existan dos millones de pesos. Eso es inconcebible en un desarrollo, eso no es equidad, eso no es política, eso no es nada, eso es hablar folclóricamente.

En definitiva, mientras el Ministerio de Educación ha insistido en ver la inserción de la lengua, la cultura y la identidad, como parte de una educación pertinente que permita alcanzar mejores aprendizajes, las escuelas que procuran una educación emancipadora mantienen el objetivo pedagógico fundamental, pero trabajan en una etapa más avanzada de vinculación escuela-comunidad. No se sienten ajenas a los objetivos políticos del pueblo mapuche ni a la interpelación por un desarrollo endógeno que rechaza la imposición de formas externas en las que "ellos piensen lo que para nosotros es bueno". Las opciones hasta ahora van por una Escuela que asuma las solidaridades entre la lengua y la situación sociopolítica del grupo que la habla vs. una Escuela con un "currículo diglósico" que mantiene la lengua en posición de saber subalterno al occidental y constriñe sus usos y enseñanza en espacios estancos, aislados del contexto vivo sociopolítico y comunitario.

\author{
Universidad de Los Lagos* \\ Departamento de Humanidades y Arte \\ Casilla 933, Osorno (Chile) \\ palvarez@ulagos.cl \\ Universidad de Los Lagos** \\ Departamento de Educación \\ Casilla 933, Osorno (Chile) \\ aforno@ulagos.cl
}


La inserción de la lengua mapuche

\section{BIBLIOGRAFÍA}

ALBÓ, Xavier. "El futuro de los idiomas oprimidos”, en Eni Pulcinelli. Política Lingüística na América Latina. Brasil: Conselho, 1988.

BARBOSA MOREIRA, Antonio Flavio. "Currículo, utopia e pósmodernidade”, en Currículo: Questões atuais. (Vários autores). Brasil: Papirus, 1997.

CARTAGENA, Nelson. "Teoría y práctica de la traducción de nombres de referentes culturales específicos”, en Mario Bernales y C. Contreras (org). Por los Caminos del Lenguaje. Temuco. Sociedad Chilena de Lingüística y Departamento de Lengua, Literatura y Comunicación. Temuco: Ediciones Universidad de La Frontera, 1998, 7-22.

CALVET, Louis-Jean. Lingüística y colonialismo. Breve Tratado de Glotofagia. Buenos Aires: F.C.E, 2005.

CONTRERAS, Constantino. (1991): "El mito del Rey-Inca en los huilliches", en Nütram, Año VII, Nº1, Instituto de Estudios Indígenas, Universidad de La Frontera, Temuco, Chile.

CORAZZA, Sandra. "Planejamiento de ensino como estratégia de política cultural”, en Currículo: Questões atuais. (Vários autores). Brasil: Papirus, 1997.

CORAZZA, Sandra: “¿Qué quiere un currículum?”, en Cuadernos de Pedagogía. Año IV, Nº 9 (octubre de 2001), Rosario (Argentina).

DÍAZ, Raúl (2001). Trabajo docente y diferencia cultural. Buenos Aires: Miño y Dávila editores.

FOERSTER, Rolf y J. Vergara (2001): "Hasta cuando el mundo sea...los caciques huilliches en el siglo XX”, en Álvarez-Santullano, Pilar y A. Forno. Fütawillimapu. Grandes Tierras del Sur. Osorno: Conadi Universidad de Los Lagos.

HERNÁNDEZ, Moriana. "La Declaración de los Derechos Humanos desde una perspectiva de género, el camino recorrido", en: http://www.gloobal.net/iepala/gloobal/fichas/ficha.php?entidad=Textos \&id=1683\&opcion=documento

HUENCHULLAN, Carolina. "La institucionalización de la educación intercutural bilingüe en Chile: contexto, situación actual y desafíos”, en Teresa Durán, D. Catriquir y A. Hernández (comp.). Patrimonio cultural mapuche. Vol II, Temuco: editorial UC, 2005.

MINISTERIO DE PLANIFICACIÓN Y COOPERACIÓN. Ley 19.253. Diario Oficial, 05 de octubre de 1993, Santiago de Chile.

NARODOWSKI, Mariano. El desorden de la educación. Buenos Aires: Prometeo, 2004. 


\section{Pilar Álvarez-Santullano - Amílcar Forno}

PINTO RODRÍGUEZ, Jorge. "La Formación del Estado, la Nación y el Pueblo Mapuche. El origen de un conflicto no resuelto". Discurso Inaugural Universidad de Los Lagos, Sede Coyhaique, 2001.

ROLDÁN, Eduardo. “¿Qué es la interlengua?”, en Documentos Lingüísticos y Literarios, N¹5, 11-12. Dirección Electrónica:

www.humanidades.uach.cl/documentos_linguisticos/document.php?id=328.

SIGUAN, Miquel. Bilingüismo y Lenguas en Contacto. Madrid Alianza Editorial, 2001.

WALSH, Catherine. “(De) Construir la interculturalidad. Consideraciones críticas desde la política, la colonialidad y los movimientos indígenas y negros en el Ecuador”, en Fuller, Norma. Interculturalidad y Política. Desafíos y posibilidades. Red para el Desarrollo de las Ciencias Sociales en el Perú. Lima, 115-145. 